\title{
EXPERIMENTAL INVESTIGATION OF SETTLING SLURRY FLOW IN INCLINED PIPE SECTIONS
}

\author{
P. Vlasák*, Z. Chára **, V. Matoušek ${ }^{* * *}$, M. Kesely ${ }^{\dagger}$, J. Konfršt ${ }^{\ddagger}$
}

\begin{abstract}
Narrow particle size distribution glass beads-water slurry flow in the pipe sections of different inclination were investigated on an experimental pipe loop of inner diameter $D=100 \mathrm{~mm}$. The study refers to the effect of pipe inclination and slurry velocity on local concentration distribution, pressure drop-velocity relationship, and deposition limit. The study revealed that the glass beads-water mixtures in the inclined pipe sections were significantly stratified; the solid particles moved principally close to the pipe invert, and for flow velocities close to deposition limit sliding bed or stationary deposit is created even in inclined pipe sections.
\end{abstract}

Keywords: settling slurry, inclined pipe, pressure drops, concentration distribution, radiometry

\section{Introduction}

Hydraulic pipeline transport is commonly used for transport of different bulk materials, e.g. in dredging, building, mining, or land reclamation (Vlasak et al., 2012). Pipeline systems used in industrial applications often contain inclined pipe sections. From operational point of view transport concentration, operational velocity and pressure drops are the most important parameters for pipeline transport design and operation. A lot of theoretical and experimental studies have been carried out on transport of sand or fine particles in horizontal pipes (Vlasak and Chara, 1999; 2009). However, a relatively little attention has been done on hydraulic conveying in vertical and inclined pipes.

The flow of settling slurry in pipe may be defined as the flow with an asymmetrical concentration and velocity distribution. Settling slurries tend to stratify in horizontal and inclined pipes. The slurry stratification, which affects the pressure drops and deposition limit velocity, depends on the angle of pipe inclination. Wilson proposed a two-layer model for settling slurries with fully stratified flow pattern (Wilson, 1976; Wilson et al., 2006). The layers differ in the local solids concentration and velocity. In each layer there is a difference in the velocities of the particles and the carrier liquid, what results in a transfer of energy from the fluid to the particles and from the particles to the pipe wall (Vlasak et al., 2017). The velocity difference between the solid and liquid phase, called slip velocity, is one of mechanism of particle movement in two-phase flow. Due to slip velocity, there is difference between transport $\left(C_{d}\right)$ and in situ $\left(C_{v}\right)$ concentrations. Friction losses of heterogeneous slurries flow in pipeline are strongly dependent on the concentration distribution (Matousek, 2002). If the slurry operational velocity is close to the deposition limit, a granular contact bed forms at the pipe invert; the bed slides along the

Prof. Ing. Pavel Vlasák, DrSc., FEng.: Institute of Hydrodynamics CAS, Pod Pat'ankou 30/5; 160 00, Prague 6; CZ, vlasak@ih.cas.cz

** Doc. Ing. Zdeněk Chára, CSc.: Institute of Hydrodynamics CAS, Pod Pat’ankou 30/5; 160 00, Prague 6; CZ, chara@ih.cas.cz

*** Prof. Dr.Ing. Václav Matoušek: Institute of Hydrodynamics CAS, Pod Pat’ankou 30/5; 160 00, Prague 6; CZ, matousek@ih.cas.cz

$\dagger \quad$ Ing. Mikoláš Kesely: Institute of Hydrodynamics CAS, Pod Pat’ankou 30/5; 160 00, Prague 6; CZ, mikolas.kesely@fsv.cvut.cz

\$ Ing. Jiří Konfršt,PhD.: Institute of Hydrodynamics CAS, Pod Pat'ankou 30/5; 160 00, Prague 6; CZ, konfrst@ih.cas.cz 
pipe wall at velocities above the deposition limit and bed forms a stationary deposit below the deposition limit velocity. The contact bed is important contributor to solid friction in settling slurry flow.

\section{Experimental Equipment and Material}

The experimental investigation was carried out on the pipe loop of inner diameter $D=100 \mathrm{~mm}$ with horizontal and inclinable pipe sections. The total length of the loop was $93 \mathrm{~m}$, the inclinable U-tube was used to determine the volumetric transport concentration $C_{d}$ of the conveyed slurry. Glass viewing sections were used to study the slurry flow behaviour and deposition limit velocity $V_{d l}$. Slurry flow was measured simultaneously in the ascending and the descending legs of the inclinable U-tube at slopes $\alpha$ varying from $-45^{\circ}$ to $45^{\circ}$. The pressure drops were measured by Rosemount 1151DP transmitters, slurry velocity was measured by a Krohne OPTIFLUX 5000 magnetic flow meter. The loop was equipped with gamma-ray density meters controlled by a computer. The studied slurry consisted of glass beads B134 (particle mean diameter $d_{50}=0.18 \mathrm{~mm}, d_{18}=0.16 \mathrm{~mm}, d_{84}=0.24 \mathrm{~mm}$, particle density $\rho_{p}=2460 \mathrm{~kg} \mathrm{~m}^{-3}$ ) and water, the transport volumetric concentration $C_{d}$ ranged from 11 to $36 \%$.
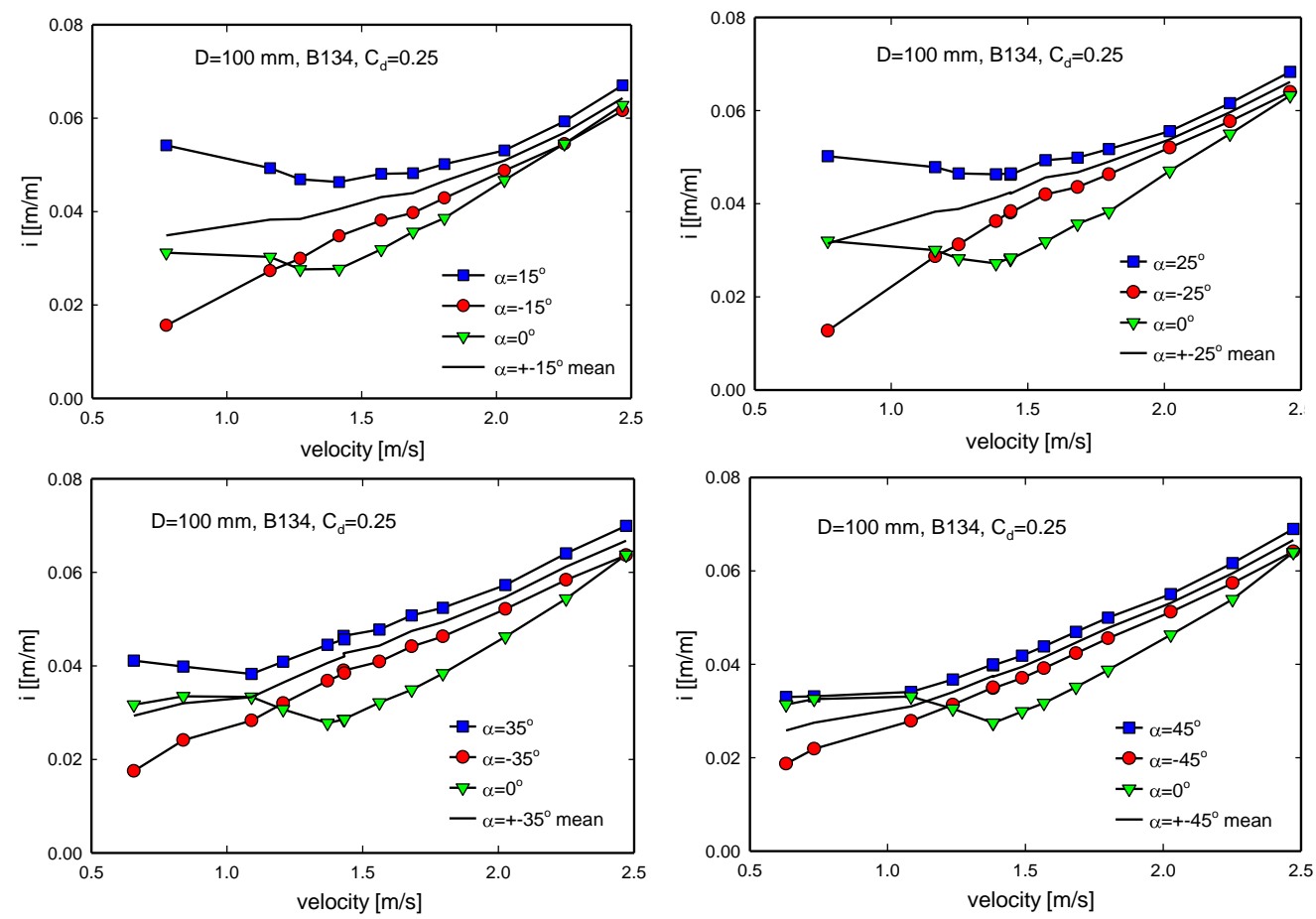

Fig. 1: Effect of the inclination angle $\alpha$ and flow velocity $V$ on frictional pressure drops $i_{f, \alpha}\left(C_{d}=0.25\right)$.

\section{Pressure gradient}

The most important flow parameter for transport pipeline design seems to be pressure drops, which depend on slurry concentration $C$ and flow velocity $V$, on conveyed particles and pipeline physical parameters, and of course on angle of the pipe inclination $\alpha$. The effect of pipe inclination on the pressure drops can be determined by using some semi-empirical correlations adapted to inclined pipes (Shook and Roco, 1991; Doron et al., 1997). Well known Worster and Denny (1955) equation quantifies the effect of pipe inclination, $\alpha$, on the total pressure drop, $I=d P / d L$, based on "the solids effect", i.e. the difference in pressure gradients between slurry and carrier liquid, $\Delta I=i_{s}-i_{L}$. For inclination $\alpha$ it is given as

$$
-\Delta I_{\alpha}=-\Delta I_{0} \cdot \cos \alpha+\left(\rho_{s}-\rho_{L}\right) \cdot g \cdot \sin \alpha,
$$

where index $s$ and $L$ means slurry and liquid respectively, $\alpha$ and $O$ inclined and horizontal flow respectively, $\rho$ is the density, and $g$ is the gravitational acceleration. The angle $\alpha$ has positive values in an ascending pipe and negative values in descending pipe. The solids effect on the pressure drops in inclined flow is a sum of two contributions - the frictional pressure drops and the hydrostatic pressure (the second term on right-hand part of Eq. 1). The frictional pressure drops $i_{f, \alpha}$ in the inclined pipe (the first term on right-hand part of Eq. 1) are

$$
i_{f, \alpha}=i_{L, O}+\left(i_{s, O}-i_{L, O}\right) \cdot \cos \alpha
$$


From Eq. (2) it follows that the frictional pressure drops at the same inclination angle should be the same for a positive or a negative slope, the slurry flow behaviour in ascending and descending pipe sections should be also the same, including the distribution of solids in a pipe cross section. It is in contradiction with experimental results, which shows that concentration distribution in ascending and descending pipes are different, and concentration profiles are sensitive to the angle of pipe inclination. The effect of pipe inclination $\alpha$ on frictional pressure drops $i_{f, \alpha}$ is illustrated in Fig. 1 for glass beads slurry of transport concentration $C_{d}=0.25$. From pressure drop-velocity relationship follows that difference between ascending and descending flow and between horizontal and inclined flow increases from horizontal flow up to about inclination angle $\alpha=25^{\circ}$, then slowly decreases. The difference decreases also with increasing flow velocity $V$. Maximum difference between horizontal and inclined flow are reached for slurry velocity close to the deposition limit $V_{d l}$. Frictional pressure drops in the ascending pipe are higher than that in the descending pipe, the difference decreases with increasing velocity and inclination.

\section{Local Concentration Distribution}

Effect of pipe inclination on concentration distribution, slurry flow behaviour, pressure drops, and deposition limit velocity of settling slurry flow was confirmed by measurement of chord-averaged local concentration $c_{v} / y$ profiles. The concentration profiles confirmed the stratified flow pattern in inclined pipe sections (Krupicka and Matousek, 2014; Vlasak et al., 2016; 2017). Local concentration reached maximum near the pipe invert, however, for ascending and descending pipe and flow velocities $V \approx 2.0$ $\mathrm{m} / \mathrm{s}$ (i.e. above the deposition limit $V_{d l} \approx 1.5 \mathrm{~m} / \mathrm{s}$ ), slope of concentration profile increased with increasing inclination angle $\alpha$, see Fig. 2 (upper panel left). Similar flow pattern was observed for velocities $V \approx 1.45$ $\mathrm{m} / \mathrm{s}$, i.e. close to deposition limit (upper panel right). For $V<V_{d l}$ and $\alpha<30^{\circ}$, a sliding or stationary beds were observed in ascending pipe and transport concentration $C_{d}=0.25$. For higher inclination angles $\left(\alpha>30^{\circ}\right)$ the sliding bed disappears. Similar behaviour was observed for lower concentration $\left(C_{d}=0.11\right)$, both for ascending and descending pipe sections, see Fig. 2 lower panel right.
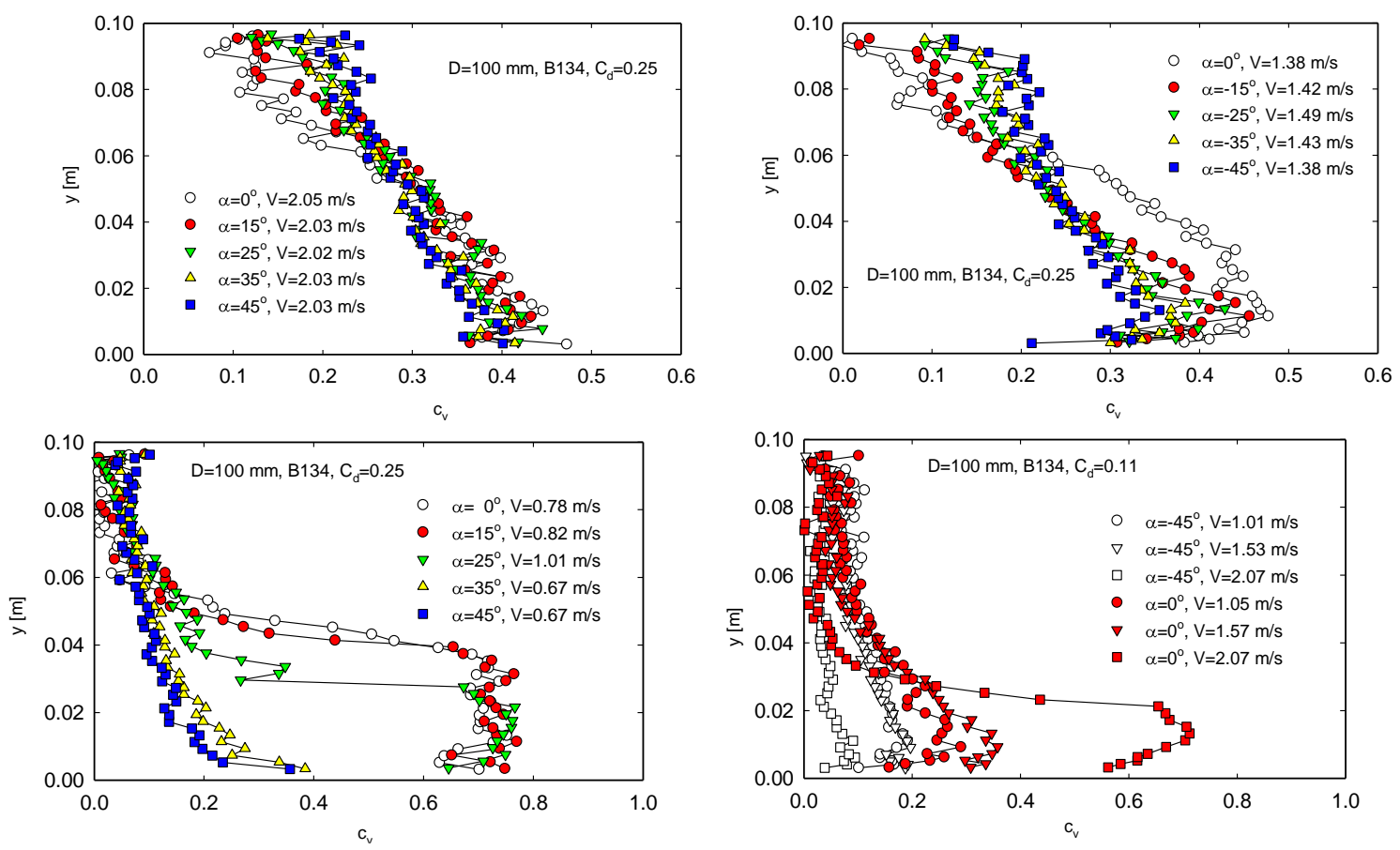

Fig. 2: Effect of the pipe inclination $\alpha$ on chord-averaged local concentration profiles.

Difference between ascending and descending flows is illustrated in Fig. 3. For low inclination angle $\alpha= \pm 15^{\circ}$ and velocity $V<V_{d l}$ a bed deposit was observed in both ascending and descending pipe legs. Bed layer in descending pipe reached substantially lower local concentration $c_{v}$ and deposit height $y$ than that in ascending pipe $\left(c_{v} \approx 0.60\right.$ instead 0.75 , and $y / D \approx 0.2$ instead 0.4$)$. For velocity $V \approx V_{d l}$ a very thin deposit was observed in ascending pipe only. For higher inclination angle $\left(\alpha> \pm 35^{\circ}\right)$ no deposit was observed. Similarly as it was confirmed for pressure drops, the effect of pipe inclination for low values of inclination angle $\alpha$ is not significant (Vlasak et al., 2014b; 2016; 2017). The local concentration in ascending pipe section is always higher than that in descending pipe section. 
Deposition limit $V_{d l}$ in ascending pipe is slightly lower than that in horizontal pipe $\left(V_{d l} \approx 1.5 \mathrm{~m} / \mathrm{s}\right)$; it decreases with increasing pipe inclination and slurry velocity. In descending pipe no deposition limit was observed for angle $\alpha<-25^{\circ}$.
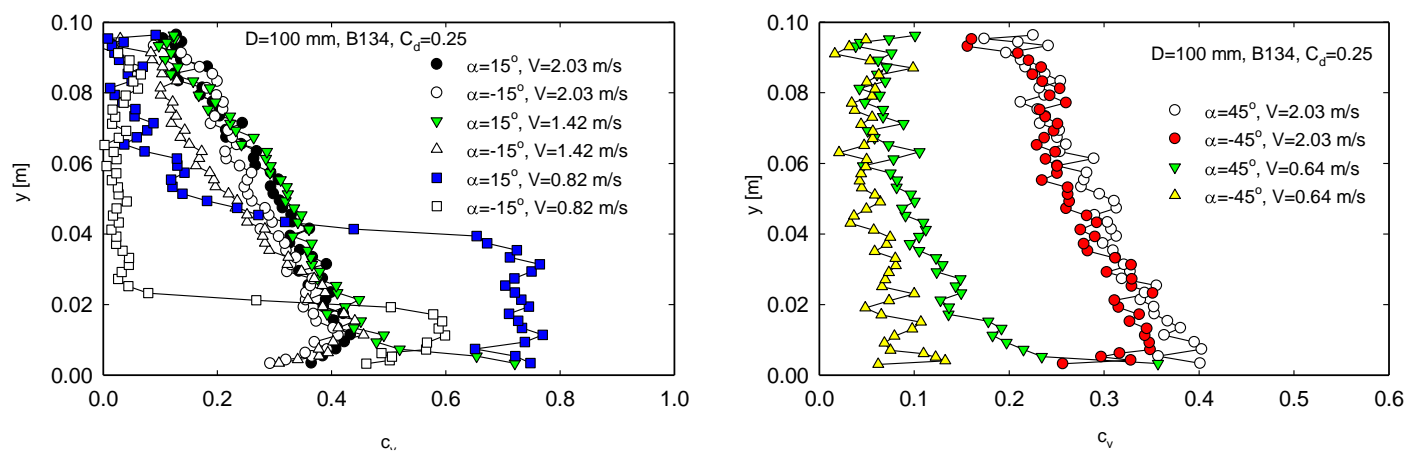

Fig. 3: Effect of mean slurry velocity $V$ on chord-averaged local concentration profiles.

\section{Conclusions}

The stratified flow pattern of the settling slurry in inclined pipe sections was revealed. For low inclination angle $\alpha$ (lower than about $25^{\circ}$ ) the effect of pipe inclination on local concentration distribution is not significant. Mean transport concentration for descending flow is always lower than that for the ascending flow. With increasing mean mixture velocity the local concentration in the bed layer decreases; this effect increases with increasing inclination angle. Deposition limit in ascending pipe is slightly lower than that in horizontal pipe; for negative pipe inclination $\left(\alpha<-15^{\circ}\right)$ no deposition limit was determined. Frictional pressure drops in ascending pipe are higher than that in descending pipe, the difference decreases with increasing velocity and inclination.

\section{Acknowledgement}

Supports under the project 17-14271S of the Grant Agency of the Czech Republic, and RVO: 67985874 of the Czech Academy of Sciences are gratefully acknowledged.

\section{References}

Doron, M,. Simkhis, M. and Barnea, D. (1997) Flow of solid-liquid mixtures in inclined pipes, Int. J. Multiphas. Flow, 23, pp. 313-323.

Krupicka, J. and Matousek, V. (2014) Gamma-ray-based measurement of concentration distribution in pipe flow of settling slurry: vertical profiles and tomographic maps. J. Hydrology and Hydromechanics, 62, 2, pp.126-132.

Matousek, V. (2002) Pressure drops and flow patterns in sand-mixture pipes. Experimental Thermal and Fluid Science, 26, pp. 693-702.

Shook, C. A. and Roco, M. C. (1991) Slurry Flow. Principles and Practice, Butterworth-Heinemann.

Vlasak, P. and Chara, Z. (1999) Laminar and turbulent flow experiments with yield-power law slurries. Powder Technol, 104, pp. 200-206.

Vlasak, P. and Chara, Z. (2009) Conveying of solid particles in Newtonian and non-Newtonian carriers. Part. Sci. Technol, 27, 5, pp. 428-443.

Vlasak, P., Chara, Z. and Konfrst, J. (2017) Flow behaviour and local concentration of course particles-water mixture in inclined pipes. Journal of Hydrology and Hydromechanics, 65, 2, pp. 183-191.

Vlasak, P., Kysela, B. and Chara, Z. (2012) Flow Structure of coarse-grained slurry in horizontal pipe. Journal of Hydrology and Hydromechanics, 60, 2, pp. 115-124.

Vlasak, P., Chara, Z., Konfrst, J. and Krupicka, J. (2016) Distribution of concentration of coarse particle-water mixture in horizontal smooth pipe. Canadian Journal of Chemical Engineering, 94, pp. 1040-1047.

Vlasak, P., Chara, Z., Krupicka, J. and Konfrst, J. (2014b) Experimental investigation of coarse particles-water mixture flow in horizontal and inclined pipes. Journal of Hydrology and Hydromechanics, 62, 3, pp. 241-247.

Wilson, K. C. (1976) A unified physically based analysis of solid-liquid pipeline flow, Proc. of HYDROTRANSPORT 4 (eds. Stephens H.S, Streat M. Clark J., Coles N.G.), B.H.R.A., Cranfield, UK, Pap. A1.

Wilson, K. C., Addie, G. R., Sellgren, A. and Clift, R. (2006) Slurry Transport Using Centrifugal Pumps. Springer, US.

Worster, R. C. and Denny, D. F. (1955) Hydraulic transport of solid materials in pipelines. P. I. Mech. Eng, 169, pp. 563-586. 